\title{
Institutional Restraint Dispel of Promoting the Transfer of Rural Labor in the Comprehensive Deepening Reform Period
}

\author{
Huanying Zhang, Xuefeng Zhang, Dexin Wang \\ Southwest University, Chongqing, 400715, China
}

Keywords: Rural Labor transfer, System barrier, System innovation

\begin{abstract}
Since the Third Plenary Session of the eighteenth Central Committee, our country entered a comprehensive deepening reform period. The central once again put forward to "promote agricultural transfer of population, and gradually transfer the agricultural population who meet the conditions to urban residents", rural labor transfer into a relatively relaxed policy stage. However, there still exists a system to restrict the transfer of rural labor force, which need to break the bottleneck of the system, and rely on public policy innovation to effectively promote the transfer of rural labor force and the process of the public.
\end{abstract}

\section{Introduction}

Since the Third Plenary Session of eighteenth Central Committee, our country entered a comprehensive deepening reform period, the central once again put forward to "promote agricultural transfer of population, and gradually transfer the agricultural population who meet the conditions to urban residents", "so that the majority of farmers participate in the modernization process, the common share and enjoy the fruits of modernization", the rural labor transfer into a relatively relaxed policy. With the promotion of urbanization strategy, the transfer of rural labor force and the public has become one of the important contents of the local government. Therefore, in the new period, how to through system innovation effectively promote the orderly transfer of rural labor force, and protect the rights and interests of rural labor transfer, and promote the sustained and healthy development of local economy is the problem local government must solve.

\section{Comprehensive deepening the new situation of the rural labor force transfer during the reform period}

The continuous promotion of the transfer of rural labor force, both macro, based on the "three rural" problem solving, the strong demand for urbanization, and micro, based on the farmers themselves want to change the traditional way of life, integrate into the reality of urban life. After the Third Plenary Session of eighteenth Central Committee, our country's comprehensive deepening reform horn has sounded, the transfer of rural labor in the new era is also facing new situation.

Firstly, the situation of economic development and the policy environment has changed significantly. 2012, China's national economic growth rate of $7.8 \%$, is the lowest point in $1999(7.6 \%)$ during the 13 years, 2013 GDP growth rate of the National Bureau of statistics preliminary estimates for $7.7 \%$. To this end, expand domestic demand, transfer of rural labor, and promote urbanization to become the government's policy objectives. 2012 China's resident population urbanization rate has reached $52.57 \%$, to achieve the "Twelfth Five Year" plan target 51.5\%, but according to the census register population rate of only $35.29 \%$, the difference is a large number of rural migrant workers whose household registration is not in cities and towns : the real "edge people" of the city. In order to solve the problem of large and medium-sized city of heavy load and the interests of this group of people, local governments have issued some policies related to the livelihood of the people, such as migrant workers into the scope of the collection of endowment insurance, gradually promote the provincial medical insurance, increase the proportion of rural Medicare reimbursement, allowing the children of migrant workers in the town to go to school, the implementation of the reform of the household registration system to "the conditions of the farmers transfer to the city" as the core content, 
and the recent implementation of the urban and rural residents pension insurance and pension insurance for urban workers conditionally merged, these policy adjustment shows that the rural labor transfer policy environment gradually showing a relaxed posture, which will directly affect the pattern of rural labor transfer, rural labor transfer more and more transfer agriculture labors choose the local employment, or families of migrant workers, changing the existing social structure and the urban population structure.

Secondly, the numbers of migrant workers are increasing, and the numbers of the transfer labor force are reducing. In the last five years, the number of workers and migrant workers are increasing, in 2012, the total number of migrant workers reached 262.61million, in which 163.36 million are migrant workers, but the absolute number of rural household registration population has continued to decrease, as shown in figure 1.

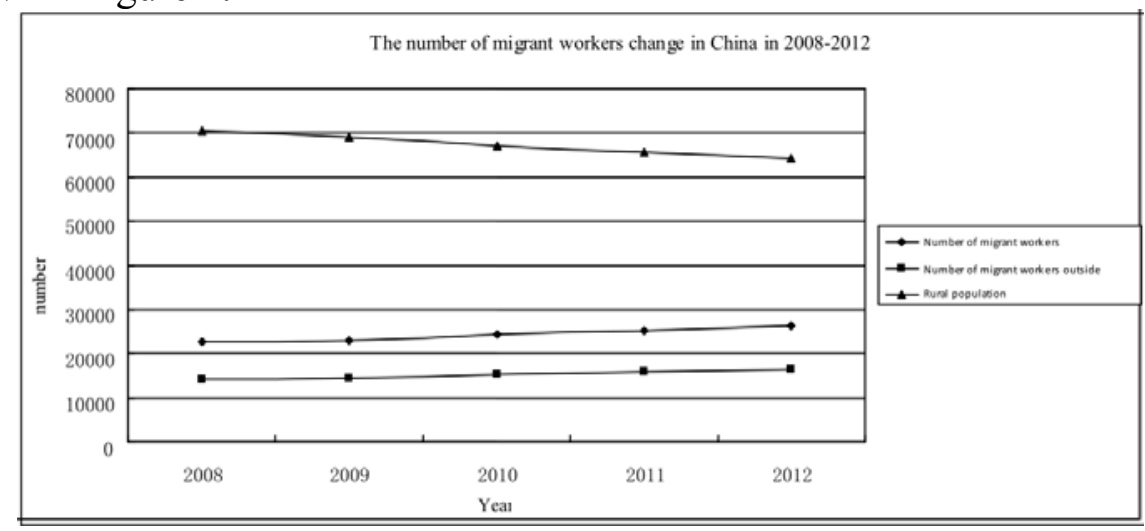

Fig. 1 The number of migrant workers change in China in 2008-2012

Data source: human resources and Social Security Department of the Ministry of human resources in every years and social security career ministry develop statistical bulletin, the annual statistical yearbook.

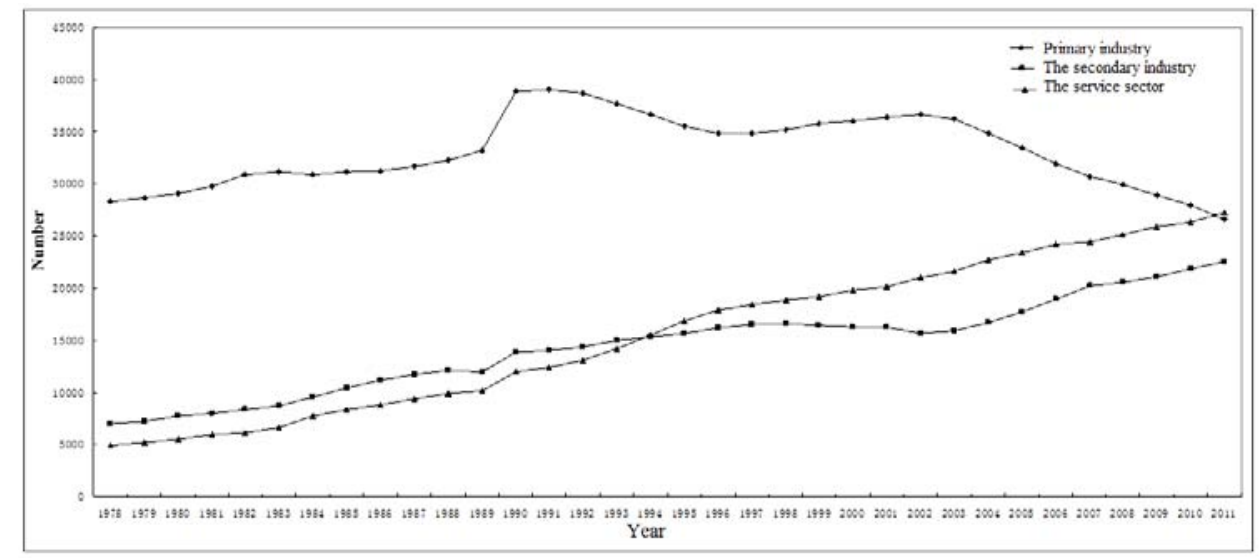

Fig. 2. Changes in the number of agricultural and non agricultural employment in 1978-2011

Data source: China Statistical Yearbook in 2012

From the employment point of view, the number of first industrial employment continued to decline, from 283.18 million in 1998 to 265.94 million in 2011. the proportion of agricultural employment declined from $70.5 \%$ in 1978 to $34.6 \%$,in 2011 , the employment of the second or third industry is gradually rising, as shown in figure 2. After decades of continuous flow and transfer, the "surplus" of rural labor has changed. As early as 2006, the State Council Development Research Center of rural economy research department of the survey on 2749 villages shows that $74.3 \%$ of the village that can go out for employment of young workers have been out, migrant workers labor market from the demand led to supply LED, and young labor is limited to [1]. The surplus of rural 
labor force in 2007 is $23.5 \%$, which is only 58000000 of the rural surplus labor under the age of 40 , and the remaining proportion is only $11.7 \%$. [3] in a sense, the young generation of rural labor force has been transferred.

\section{Institutional constraints on the transfer of rural labor}

Throughout the history of rural labor transfer, land system, household registration system, employment system, social security system for rural labor transfer and the process of rural migrant workers' citizenship influenced greatly. Every time the government system and policy is loose, the transfer process will accelerate. However, because of the path dependence effect of the existing system, the reform of the short time is difficult to carry out the fundamental reform. In the comprehensive deepening of reform, the rural transfer of labor can become a real "city people" depends on the process of its citizens must face several obstacles: household registration, employment, children's education and quality of life, and agricultural scale management depends on the reform of rural land system and agricultural personnel training. Specifically as the following aspects of the system constraints:

\section{The household registration system.}

In the strict sense, the household registration system can not strictly restrict the flow of rural labor force, because the flow of the rural labor force are carrying on all time, its function is mainly reflected in the quantity and quality of the rural labor transfer. The research shows that, since the reform and opening up, despite the increase in freedom of labor mobility, the Chinese household registration system has not changed in essence, the rural labor mobility is still severely limited [4]. The reason is system which is attached to the household registration system, which reflects the "Social shielding" effect of the urban and rural areas, which will be excluded from the urban resource allocation system, which has the resilience of the identity card, which seriously hinders the process of urbanization of migrant workers [5]. In the last round of household registration system reform, the local government is committed to promoting the transfer of some local household population, especially the rural population of the city suburbs, and through the establishment of strict barriers to entry, conditional, in single direction accept the high quality of foreign population (also including the field of rural population), the transfer application. In fact, more not qualified, living for many years of ordinary rural labor but not by the government's "scoring" to cross the threshold. The awkward reality can be demonstrated through the performance of a group of the latest data, namely according to the all China Women's Federation survey in 2012, China's rural left behind children reached number 61.0255 million, the scale of floating children reach 3581 million people. [6]. The parents of these children are not incorporated into the reform of the household registration system, according to the current policy is difficult to free, completely transformed into the public.

\section{The rural land system is not completely economic}

In the rural areas, the most fundamental security is the land, including rural land, homestead, household Plot, hilly land and contracted land. For farmers, the land as a production factor has the function of property income and social security. Rural land, especially the homestead, is Chinese farmer's largest property, the protection of farmers living requirements, but cannot through the sale, lease, mortgage, etc. Because of the law, the agriculture land belongs to the collective ownership, because of lack of "personal representative", the actual rights mainly belongs to the village cadres, most of the land is through the government to take over for use in the name of "public" , Compensation for farmers' standard of far lower than the market value of land, the vast majority of land acquired by the local government and investment in the industrial and commercial capital, less part of the land roam in the rural collective organization, the contract right, participate right, appeal right of the farmers is difficult to be guaranteed. 


\section{The lack of urban employment training system}

According to the survey, in 2011, migrant workers in the acceptance of secondary school or above culture education are only $9.8 \%$, not to accept any professional skills training of migrant workers accounted for $68.8 \%$, respectively, in 2012 rose to $10.4 \%$ and $69.2 \%$ [7]. This group of data shows that in the existing education system, the degree of migrant workers to receive education and the opportunity to gradually increase, but overall is not enough. From the employment perspective, in 2011, the main areas of migrant workers occupied are still manufacturing (36\%), construction $(17.7 \%)$, service $(12.2 \%)$, and so on, which are manual labor, alternative is very strong, competitive, and poor, tired, poor job. From the point of view of income, the end of 2012, the per capital monthly income of migrant workers is 2290 yuan, compared with the National Urban Non private units of the average monthly wage (3897 yuan), a difference is 1607 yuan, which is a large gap.

\section{The division of social security system}

At present our country has already formed the social security system for the three kinds of different people, which targeted the social security system of the urban workers, farmers and urban residents mainly include medical, pension insurance. Because of the difference of the financing mechanism, the farmers' security level is the lowest, and the main reason is that the farmers' own insurance costs are lower and the government's financial subsidies are insufficient. And for migrant workers, the phenomenon of the same work with different pay can be found everywhere; many enterprises do not have the legal provisions of the formal contract should be signed with migrant workers, did not pay "the five funds", migrant workers in the city of limited social security, welfare and poor.

\section{The institutional restraint dispel of promoting the transfer of rural labor in the comprehensive deepening reform period}

The history of rural labor transfer in developed countries shows that providing a sound system is a successful way to solve the rural labor transfer. In the long run, the real solution to the problem of rural labor transfer requires all levels of government from the perspective of urban and rural areas reshape the relationship of urban and rural areas, and to adjust the original institutional framework. Through appropriate public policy choice, strengthen the market of rural production elements of the allocation, through the adjustment, improve, reform or replacement to regulate and constrain the relevant interests of the parties - government, enterprise, rural labor force, to stimulate the three respective power and role, to promote rural labor can transfer and live in the city, to achieve the transfer and the synchronization of the public.

\section{Turn the household registration system management back, and enhance the attractiveness of small and medium cities}

In the early period after the founding of new China, the original intention of the establishment of the household registration system is in order to facilitate the management of the floating population, but later in the period of planned economy, because gave priority to the development of the industry in our country: a strategic choice and then Public Finance Co., through the products of workers and peasants "price scissors" to obtain agricultural security surplus industrial and agricultural population flow to ensure the welfare of urban population of public policy, so as to gradually build up the different urban and village household system wall. At present, the household register as the transfer of rural labor force into the city's step and hurdle, the as a mandatory social identification tag, hindering they share peculiar to many social welfare like the people in the town, has also become a "fled North Canton", "fled to North Canton" root of two contradictory behavior selection.

\section{Reform the Rural land system, to protect the land rights and interests of rural labor}

China's rural land belongs to the collective, property right is not clear. The distribution is administrative village, group to "land average" basis, small scale of operation of land, it is difficult to 
compete with the market risk, less and less adapt to the agricultural modernization needs. In the land transfer is not free today, in order to protect the land rights and interests of more rural labor, we must promote the reform of rural land system. First in the land property rights, in the premise of adhering to the collective ownership of rural land, give the farmers the real right for land contractual management rights of the property, implemented land inheritance, mortgage, transfer, exchange, and other functions, restrict the township government and village committee of land management behavior, so that farmers can truly free, autonomous make decision of the use and plan of the land.

\section{Increase the rural human capital investment, broaden the channels for the empowerment of rural labor force}

To make the rural labor smoothly settled towns, it must make it have the necessary employment skills, enhance their human capital. This needs to take measures from the following aspects. One is to enhance rural education: continue to increase investment in basic education in rural areas, adjust the layout of primary and secondary schools and layout, reduce the number of boarding pupils; continue to promote urban and rural primary and secondary school teachers in rotation system, broaden the scope, expand the number of rotation, and improve existing teacher performance pay system, through the wage differential guide urban teachers to teach in rural areas; improve rural students to enter universities and vocational schools the proportion of and speed up the process of building the children of migrant workers in city entrance and different college entrance examination system; break local protectionism, unified by the amount of the number of candidates to determine the proportion of college admission system of college entrance examination, so that more rural have more equal opportunity for schooling. Two is increase the vocational training on rural labor, so that they can better adapt to the city.

\section{Establish urban and rural social security system and public service system}

Transfer of rural labor is difficult to become the city's most important system is the threshold of the household registration system, and the reform of the household registration system is difficult to promote is because of the great difference between social security and public services in urban and rural areas. In term of pension and medical insurance, there are treatment problems, the convergence of the system to determine and adjust, balance of the social security fund and the construction of social security service system problem [8], therefore, one to speed up the implementation of the existing urban and rural social insurance system, and promote the organs and institutions of the pension reform as soon as possible; two to accelerate the integration of the three medical insurance, to reduce the gap between urban and rural areas; three from the management mechanism, transfer procedures, payment and other aspects of the establishment of a national network of pension, medical database, identity identification to establish personal database; four to strengthen the construction of small and medium-sized city and rural area education, community services, hospitals and other public services, public service personnel big, small and medium-sized city rotation system, implement regional wage difference system, guide the talent "to the countryside".

\section{Acknowledgments}

Fund projects: The Humanities and Social Sciences Youth Project of the Education ministry (11YJC630281); The central university basic special scientific research business fee (SWU0909602); Southwestern University doctoral technology and research project (SWU1309305).

\section{References}

[1] HuangNingyang, WanZheqin, RongYu. In the new period of Chinese rural labor force non-agricultural employment new characteristics. Research world, 2010 (5): 27-29.

[2] CaiFang. The rural surplus labor force to crack the mystery . China population science, 2007 (2):2-7. 
[3] 2011, 2012, China's migrant workers survey report [DB/OL],National Bureau of Statistics: http://www.stats.gov.cn

[4] Qiao Mingrui et al. Division of labor market, account for the difference between urban and rural employment of . Chinese population science, 2009 (11): 32-41.

[5] LiuJianping, China of rural land system reform and research . Zhongzhou Journal, 2011 (5): $72-77$

[6] The research group of the National Women's Federation, children, urban and rural status of migrant children left behind in rural China Research Report [DB/OL], People's network: http://acwf.people.com.cn/n/2013/0510/c99013-21437965.html

[7] ShenKunrong, YuJixiang. The impact of rural labor mobility on the income of urban residents in China -- Based on the perspective of the division of labor between urban and rural areas in the process of market research. Management world, 2011 (3): 58-65.

[8] Yin Wei China. To strengthen top-level design, in-depth study of human resources and social security issues . Xinhua digest, 2012 (16) 